\title{
Different Residential Forms under the Evolution of Urbanization
}

\author{
Hanwen Hu \\ Urbanism, Architecture Urbanism and Building Sciences, Delft University of Technology, Delft, The Netherlands \\ Email: huhanwen2017@163.com
}

How to cite this paper: Hu, H. W. (2019). Different Residential Forms under the Evolution of Urbanization. Current Urban Studies, 7, 587-597.

https://doi.org/10.4236/cus.2019.74031

Received: November 7, 2019

Accepted: December 9, 2019

Published: December 12, 2019

Copyright $\odot 2019$ by author(s) and Scientific Research Publishing Inc. This work is licensed under the Creative Commons Attribution International License (CC BY 4.0).

http://creativecommons.org/licenses/by/4.0/

\begin{abstract}
Residential areas are an important part of the city. The form of the settlement reflects the overall city fabric and the feelings of the living space of the residents. The contemporary European settlements show the characteristics of multiple changes under different residential theories. This paper first summarizes the development of housing theory under different urbanizations, and then analyzes the settlement forms and space with Hilversum as an example, focused on what is important for residential areas in different contexts. Finally, starting from the current situation of Hilversum, combined with the current urbanization development it discusses the trend of its residential form.
\end{abstract}

\section{Keywords}

Urbanization, Residential Form, Diversity

\section{Introduction}

Urban settlement is an important component of the human settlements. The urban settlements discussed in this paper refer to urban areas or blocks dominated by residential functions. The "morphology" is not only a description of the existence, but also a research method. For the urban and architectural fields, the "morphological method to analyze the social and physical environment of the city can be called urban morphology" (Gu, 2001). The form of settlement directly reflects the urban form to some extent, and the shape of the settlement is directly influenced and constituted by the architectural form. From the ideal community, the new town movement, the neighborhood unit, the pedestrian neighborhood block (PPC) to the traditional neighborhood development model (TOD), the residential area theory at each stage is to solve the main social problems, and gradually move towards relatively mature. In contemporary settle- 
ments, people focus on how to organize a healthy community.

Through systematic understanding of the theory of settlements under urbanization, this paper divides the development of European settlement theory after the industrial revolution into three parts: early urban theory exploration, material function rationality and urban renewal under the guidance of humanistic theory, expounding the theory of settlements, taking Hilversum as an example to analyze the physical form of settlements in the corresponding urbanization state, and theories under different urbanizations. The theory of settlement formation under different urbanizations is related to the types of forms presented, but all involve the influence of social forms on them, expanding the understanding of the possibility of physical space of settlements, and analyzing the current development trend of Hilversum, try to find a favorable development direction for the future residential area form corresponding to urbanization development.

\section{Development Process of Residential Area Morphology}

\subsection{Early Urban Theory Exploration-Garden City}

With the first industrial revolution in the 18th century, a large number of cities in Europe produced unprecedented expansion, and the population density reached a special height. At that time, the theoretical guidance of urban planning had not yet been formed, and the urban infrastructure was weak and could not meet the new production and living requirements. This formed a very chaotic and harsh living environment. Some ideal reformers proposed the idea of constructing an ideal community or an ideal city. For example, Robert Owen proposed the Agricultural Cooperatives program, hoping to establish a mixed community of agro-industrial workers to solve the social conflicts and workers' housing problems at that time.

At the end of the 19th century, the British E Howard published the book "Tomorrow-The Road to Peace for Social Reform". For urbanization, he proposed the idea of "Garden City" (Figure 1). It advocates combining the advantages of urban and rural areas, integrating park green space into urban land use planning, constructing gardens in urban centers, and arranging public buildings, commercial areas, and residential areas in a circle around the circle. The outermost area is the industrial area, surrounded by railways, surrounded by green areas and surrounding farmland (Stephen \& Ward, 1992). Six boulevards radiate from the central square, and the entire green space forms a complete system, and with the self-sufficiency urban development model and the reservation of permanent green belt around the city to prevent the city from expanding. The concept of garden city has far-reaching effects, the garden village, garden suburb, satellite town and new town were international variants that were built on the conceptual foundations of the garden city (Graham Livesey, 2011).

\subsection{Functionalism}

At the beginning of the 20th century, Europe still faced the problem of housing 


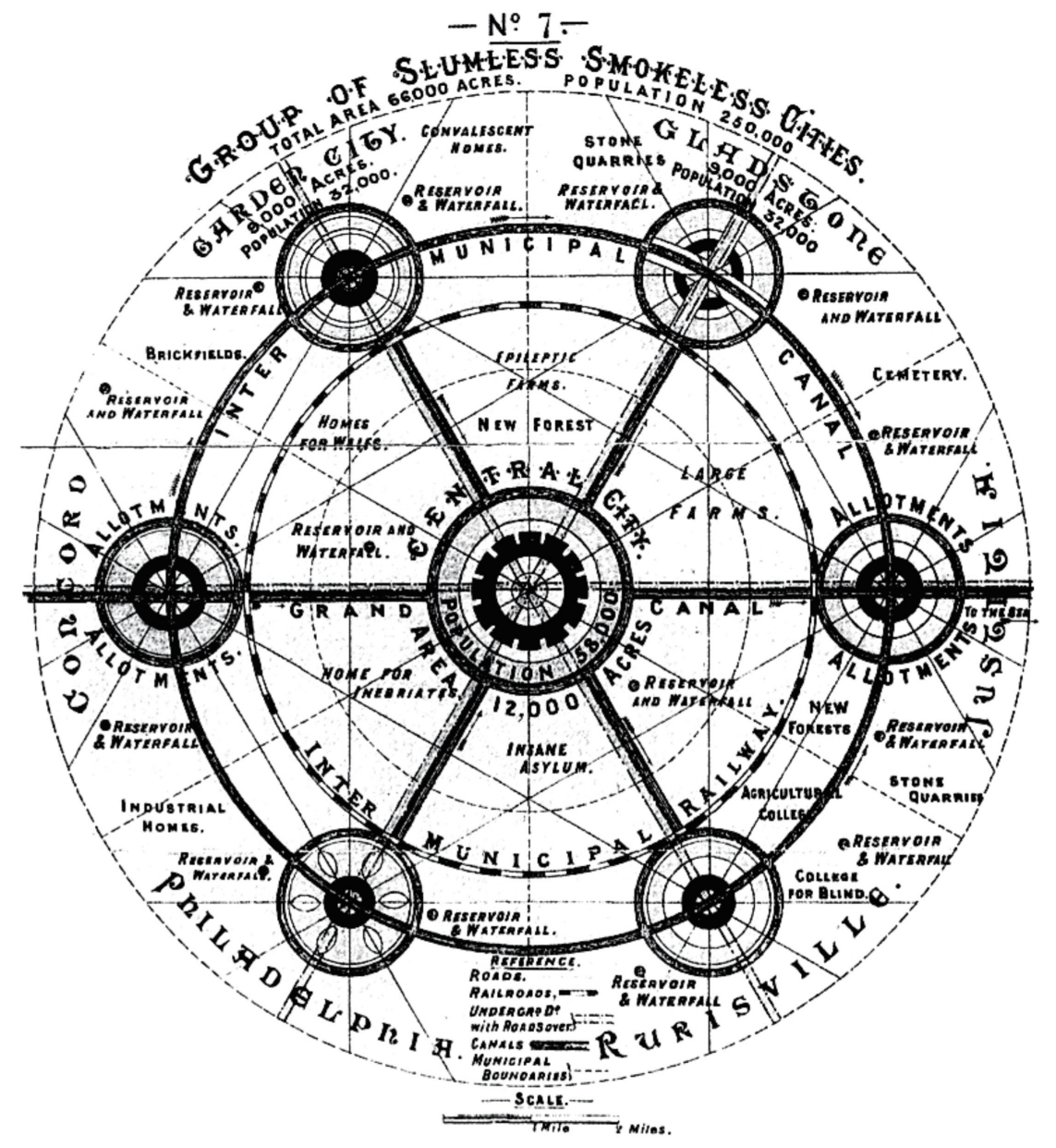

Figure 1. Garden city (Source: website).

shortage. Modernist ideas came into being. The functionalism made the urban settlements show different forms. Mies van der Rohe, Walter Groupius and Le Corbusier, they sees the city as a machine, and believes that "urban form" should follow the "city function". In the Bright City "project proposed by Le Corbusier, it shows the prototype of functional city", emphasizing the development mode of tower-like city with sunlight, air, open space, functional partition and geometric form. At the same time, under the impetus of the Athens Charter and the relatively rational study of settlement morphology from Gropius, functionalism was quickly spread. Among them, the disintegration of traditional blocks and the dramatic changes of urban fabric are most obvious. The residential areas in this period are mostly arranged in point or determinant, with large living spaces and strong spatial permeability, but the outer space was monotonous. The traditional street interface no longer exists. Some of the monolithic buildings are highly aggregated and have a large volume, and correspondingly form a large scale block.

In 1929, American architect Perry proposed the "neighborhood unit" theory (Figure 2). The central unit of the unit is a public center, and commercial and 


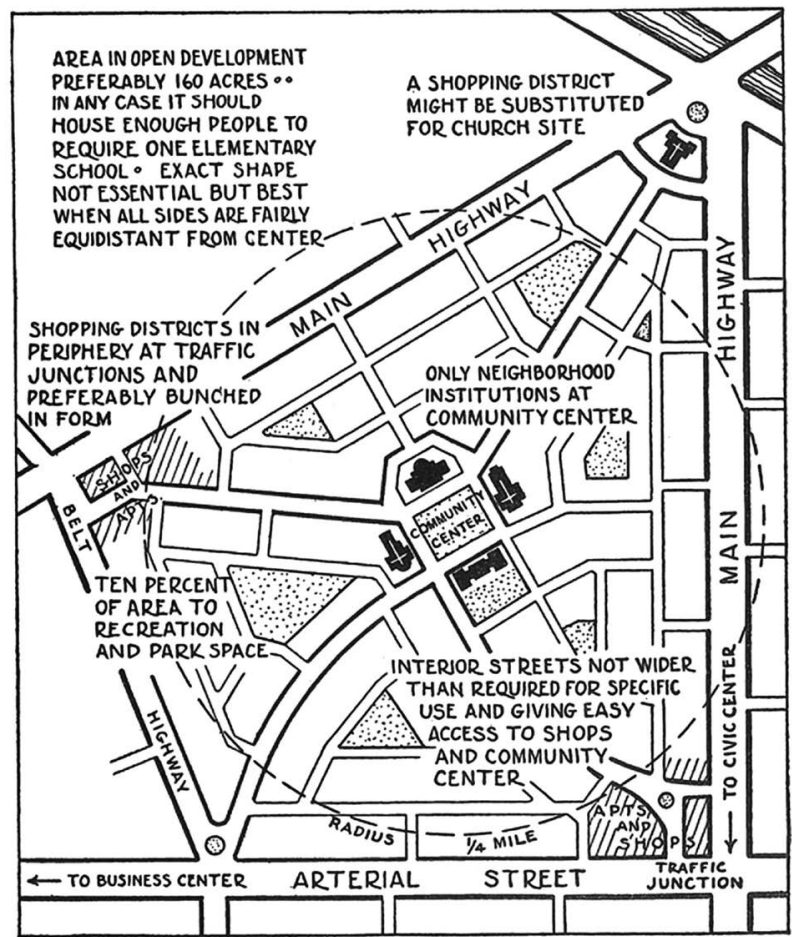

Figure 2. The basic components of Clarence Perry's neighborhood unit (Perry, 1929).

service facilities are arranged near the intersection of the main roads. Here, the traditional neighborhood houses are abandoned, and the new houses are planned to be grouped. This kind of planning model is actually the result of the automobile era in the United States after the 1920s, the large-scale suburbanization of the city, and the product of the middle class dream (Alexander, 1965). It separates the residential area from the urban planning system and deeply considers the scale of the residential area, laying a foundation for the planning of modern urban residential areas.

\subsection{Humanism-New Urbanism}

The proliferation of zoning regulations in the twentieth century is unprecedented in the history of urban design (Howard, 1985). The functionalized hierarchical urban spatial structure and the fixed living mode of neighborhood units have become new obstacles to residents' free contacts, leading to the inability to cross-integrate and create diversity among functions. So people began to think about how to improve the humanized interaction space of residential areas that material functionalism ignores after the 1960s.

In the 1960s, Jane Jacobs criticized the lack of vitality and over-emphasis on functional divisions in the big cities of the United States in his book- "The Life and Death of Big Cities in the United States" (Ewart \& Culpin, 1993). At this time, research methods of environmental behavior, environmental perception and environmental cognition have gradually emerged. Norberg Schulz puts forward the concept of place spirit, emphasizes the importance of creating local 
style and meaningful space, and criticizes the development of urban space under the influence of functionalism, and believes that traditional urban texture, sense of encirclement, space and the relationship with the natural environment no longer exist.

Then, the traditional neighborhood development model (TND) (Figure 3), the Avani Declaration and the new urbanism have emerged. Among them, the new urbanism combines the results of the neighborhood unit, the garden city and the new town planning in the suburban settlement planning, rethinking the problems of excessive use of cars, urban expansion, and suburbanization caused by single-function land use division (Huang, 2014). In the later period it emphasized the walking of friendly streets, human scales and diversity of residential planning.

\section{The Residential Form of Hilversum in Different Periods}

\subsection{Garden Area-Peripheral, Determinant-Before 1930}

The garden area is located in the south and east of Hilversum. Its residential form consists of two or three floors of enclosure houses and a small number of determinants. Plan Oost is located in the eastern part of Hilversum and consists of an east-expanded building designed by Dudok (Figure 4). The residential area is connected with each other to form a block, form a street, and enclose a square to form an organic urban form. Since 1915, Hilversum has urgently needed new working-class housing, when the municipal housing company led by Dudok would create more than 550 housing units. The entire project was influenced by the garden city movement. In order not to disturb the rural character of Hilversum, Dudok thought of low-rise dwellings and longed for-minimizing the

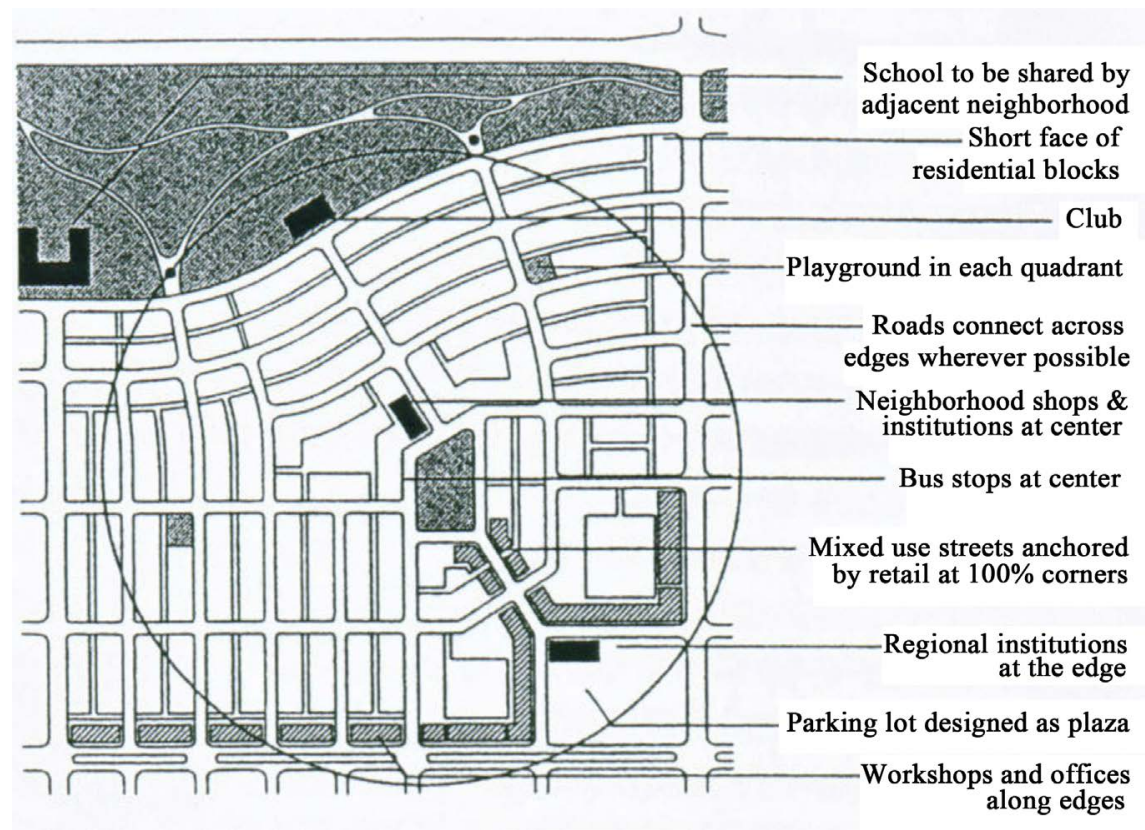

Figure 3. The new urbanism renaissance for TND (Source: website). 


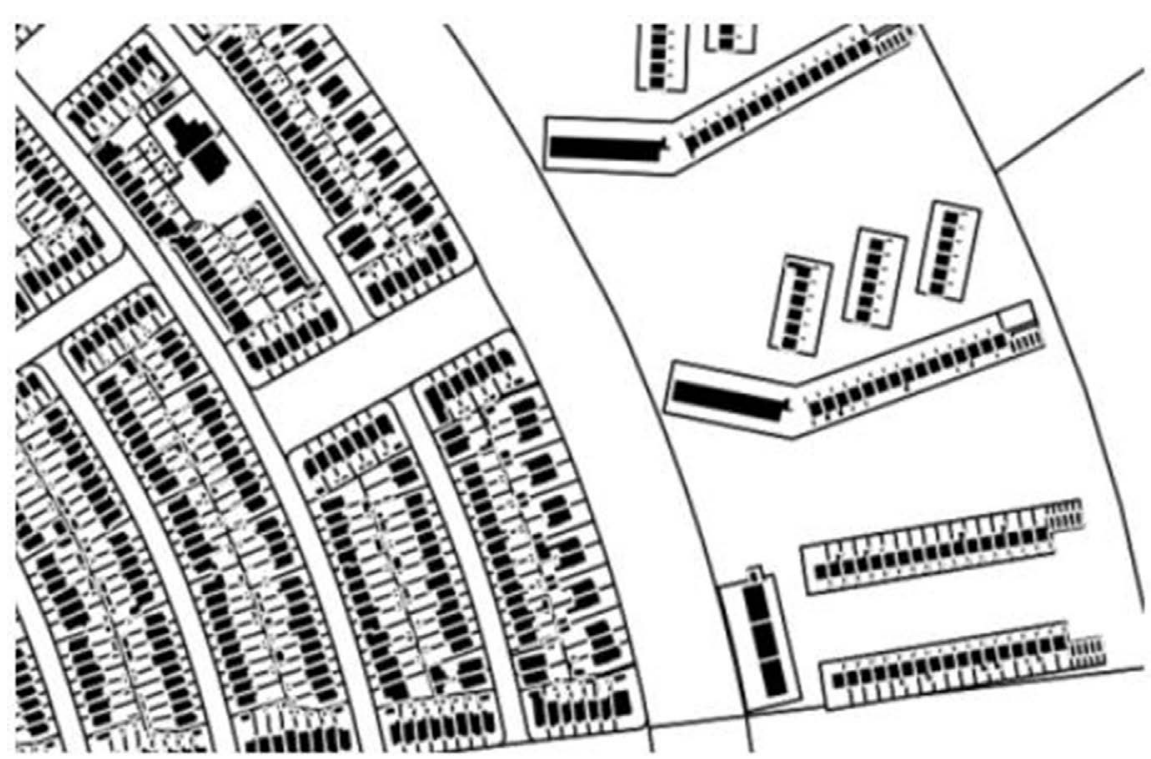

Figure 4. Plan Oost (Source: author drawing).

building. Later,-special buildings were used-such as churches, schools, reading rooms, and urban greening in the extended area to against monotonicity and diversifying houses, and due to the influence of the garden city movement, $\mathrm{Du}$ dok created a good continuous circular road. The street can be regarded as the visual axis, starting from a church, school or other special building, forming a relatively independent small-scale neighborhood.

In terms of space, the traditional surrounding houses have relatively closed features (The left part of Figure 4). Through the enclosure of the house, the space inside and outside the city is distinguished. The interior refers to the inner courtyard synthesized by the building, and the external space refers to the city streets and open spaces between blocks. In the urban space formed by this layout mode, the street interface is the facade of the building, and the interface is continuous, and the inner courtyard is relatively private and has a strong sense of field.

In greening, compared the detached residential to the surrounding houses, the surrounding houses not only the land utilization rate is higher, but also the private garden and independent households are satisfied. The green front garden and the continuous green belts of the street combine with the street trees to create a tranquil garden atmosphere.

\subsection{Post-War Residential Area-Determinant, Group Type-Before 1960}

Most of the post-war residential areas are located on the edge of Hilversum, mostly in determinant and surrounding style. European determinants were born in the early 20th century. Under the premise of limited economic conditions and a large number of residential needs, the architects opened the closed blocks, the 
multi-storey residential buildings are arranged in parallel in a good orientation and spacing to form a determinant house (Teng, 2007). The Noord area is located in the northeast (Figure 5), expanding for the early postwar period and has a strong main structure. At the same time, there are many social-friendly shops and buildings nearby.

In space, Jan Gehl believes that the interaction between architecture and the street is closely related to the number of buildings. The relationship between the street level and the high-rise buildings was clearly lost after 5 floors (Jan Gehl, 2010). The post-war residential area of this period mainly maintained the low-rise architectural form, which did not reflect the large-scale morphological features of the functionalist in the same period, but compared to the enclosed residential, it has larger spacing between determinant houses and the outside also has a large open space, creating a relatively homogeneous living condition and landscape environment. The natural landscape penetrates the living area through the gap between the rows and columns, and has a strong sense of space penetration into the city. The cemetery in the center strengthens the centrality of the area, and open design around the cemetery.

In greening, a large number of public greens and repeated determinants are used as basic units, greening on a spatially oriented road has coherent consistency, while determinant houses on the edge of Hilversum allow more open green spaces to be integrated into the community. At the same time facing the vast nature reserve; On the other hand, Kerkelanden in Hilversum is a post-war extended area that more or less reflects the characteristics of the neighborhood units (Figure 6), surrounded by urban roads, adopting the end of the road model, and the new houses are planned into groups. Schools, schools and other neighborhood services are located in the center of the neighborhood unit.

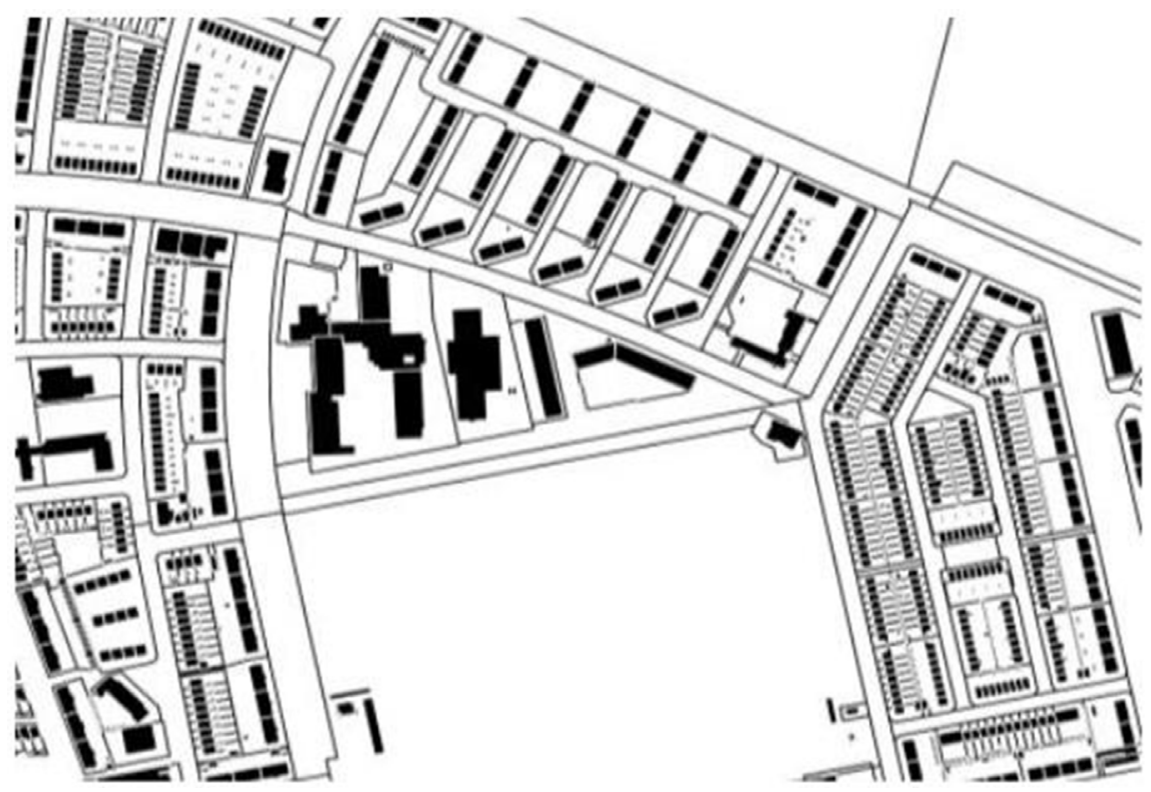

Figure 5. Noord (Source: author drawing). 


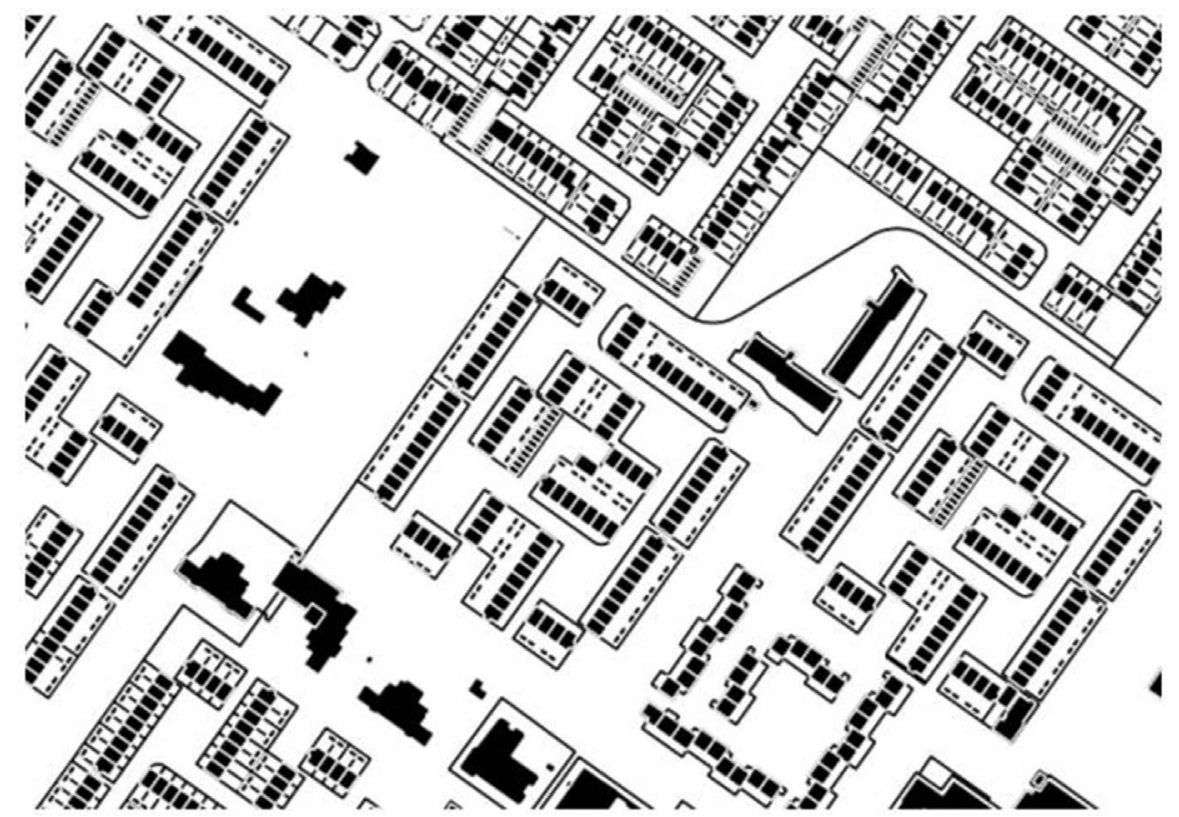

Figure 6. Kerkelanden (Source: author drawing).

In terms of space, group-style settlements have more obvious spatial organization, and the community center is stronger. In greening, more greening is incorporated into the community and there is an open space between the city and the private.

\subsection{Urban Expansion Area-Distributed, Hybrid-Before 2005}

Most of the urban expansion areas have formed a transition to the natural area in a small way, including urban filling plans and urban renewal. Its residential form is mainly composed of distributed and mixed type. Park Diependaal is located in the south of Hilversum with an axis of view pointing to the inner city and has a clear and open structure (Figure 7). At the same time, the distributed type residence can face the large-scale natural environment in the south with a more open attitude. The road scales in the block are pleasant, and different types of houses are highly recognizable. Spatially, distributed residential areas have more spatial permeability than determinant settlements, especially for areas with good landscapes, they can avoid excessive occlusion and spatial isolation from continuous building façades, but at the same time lack the enclosure of external space. They may lead to the dispersion of the external space, and the loss of the overall sense of the space and recognizability. A certain degree of defragmentation of the scattered volume can provide a more consistent spatial layering.

In the greening, this area is close to public parks and nature reserves, there are a variety of landscapes between the houses, which can effectively create a sense of privacy while having a good view. However, the accessibility of the peripheral green space is not high, and it is divided by the hedgerow. At the same time, the overgrown nature will block the line of sight from forming a boundary. 
In the filling plan, different types of settlement structures will form a mixed form and become a more open block. Located in the eastern part of Hilversum, Plan Simon Stevin was a small block in the 1930s with some detached houses (Figure 8). Many small gardens are well preserved. The radial path of the brick structure and the subdivision derived therefore are characteristic. Mixed, determinant and enclosed mixed blocks can be seen here. The flexible open space inside adds vitality to the city and provides a good foundation for different functional sites. The rich architectural form also creates different forms of greening, adding to the sense of place.

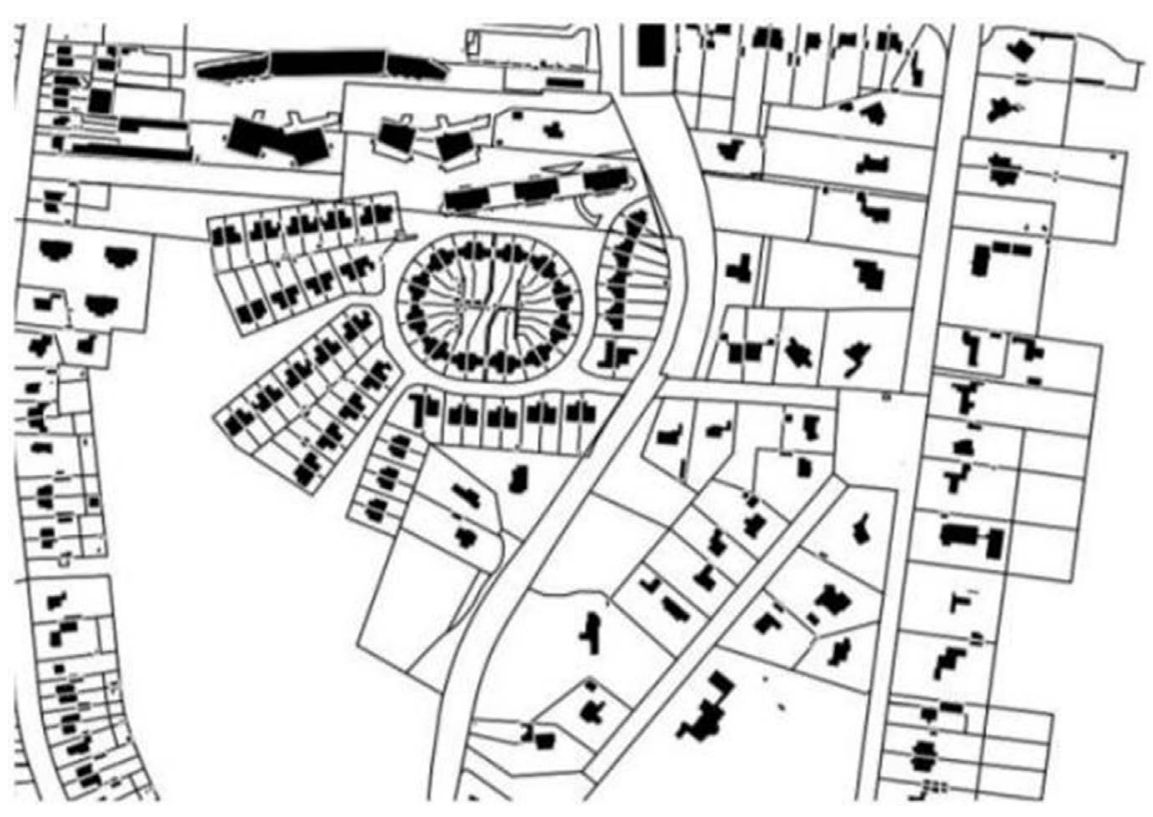

Figure 7. Park Diependaal (Source: author drawing).

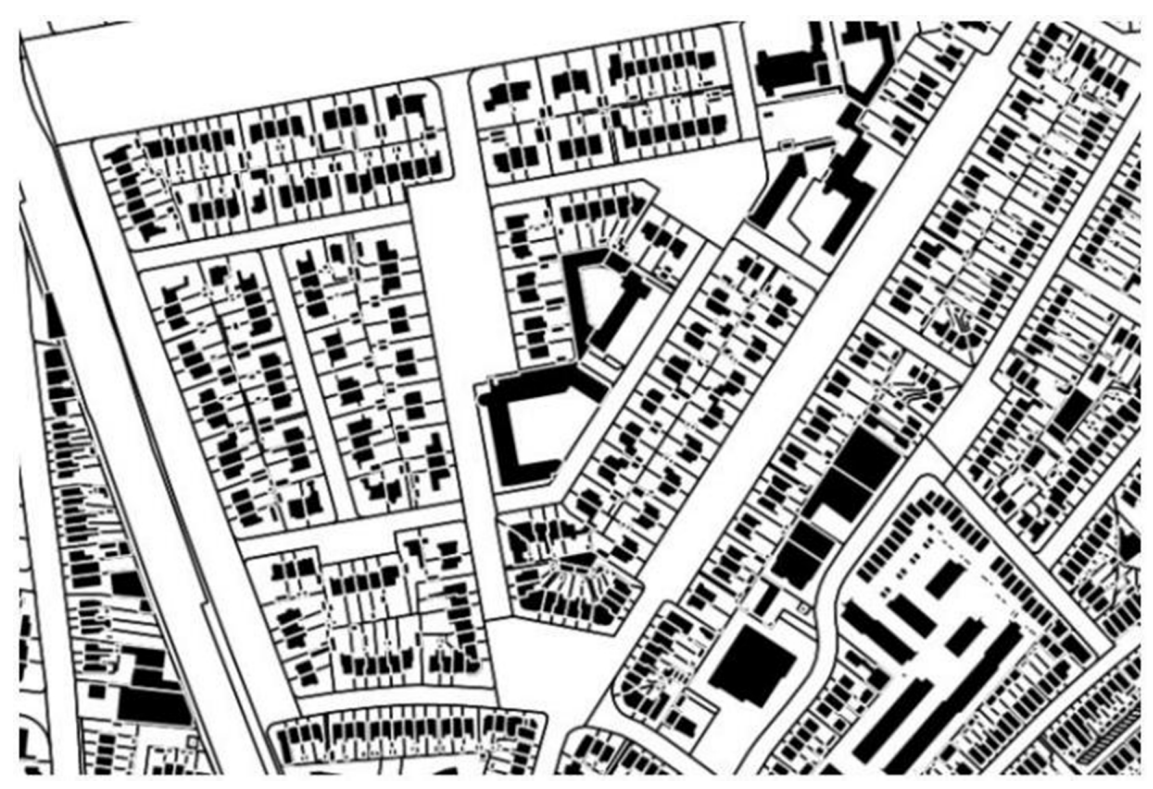

Figure 8. Plan Simon Stevin (Source: author drawing). 


\section{Conclusion}

It can be seen that the form of the settlements varies in different periods according to the needs of the people, from the ideal community derived to the rapid urbanization and housing. Under the guidance of the functionalism of demand and the theory of humanities, people have turned their attention to the livability and traditional interpersonal communication of the community.

Through the combing of different residential forms of Hilversum, although Dudok self-consciously presented himself as an artist, and Hilversum was his personal work of art (Cor Wagenaar, 2015), in physical form, it better reflects the concept of garden city and solves the problem of living in Hilversum workers. With the self-sufficiency urban development model, it has complete urban functions including commercial, industrial, educational, etc., the surrounding nature reserves not only effectively limit the spread of the city but also prevent the closure of Hilversum from outside towns. It gives Hilversum a unique and good ecological environment. Its settlement form has not been influenced by functionalism, strictly controlling the height of the building, and maintaining the characteristics of Hilversum between the country and the city. From the form of housing, it is divided into five types: enclosure, determinant, distributed, group and hybrid (Figure 9), which reflects the consistency of the harmonious community pursued by Hilversum's community building and urbanization.

These types of settlements, in terms of spatial permeability, from the strong to the weak, are distributed, determinant, group, hybrid and enclosure. The lowest residential density is the distributed type, and the hybrid type has the highest flexibility, and various factors can be adjusted during the design process. The overall form of settlements is humanized and diversified (Zhao, 2007).

From the perspective of space and greening, the future development of Hilversum in the inner city can be implanted in different residential forms, enclosing a more flexible space, focusing on the human scale, increasing the penetration of the neighborhood and creating more active neighborhood space. In greening, it is more important to consider its accessibility rather than simply increase greening. Based on good walking and public transport systems, Hilversum can become a new garden city under the new urbanism.

\section{Limitations}

The study of European urban settlements has helped to understand the possibilities of diversified housing design in different periods, and provided many examples. The purpose of the research is to change the stereotyped residential form
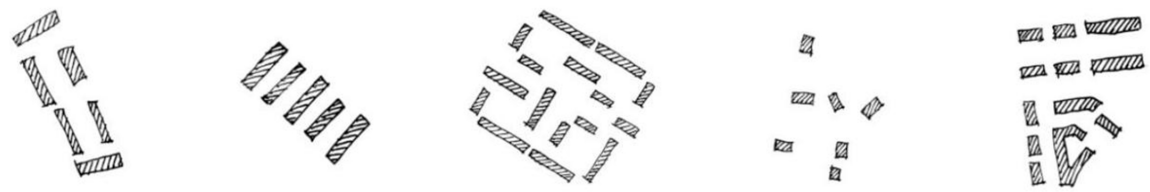

Figure 9. Enclosure, determinant, group, distributed, hybrid (Source: author drawing). 
design and serve as a reference and guidance. However, given the differences in national conditions and social environment in different countries and regions, whether the settlement pattern mentioned in the article can be applied to other regions is worthy of further research and demonstration. In addition, this paper does not discuss whether it affects the form of settlements from the aspects of climate sunshine conditions or ventilation, and it needs to be improved in future research.

\section{Conflicts of Interest}

The author declares no conflicts of interest regarding the publication of this paper.

\section{References}

Alexander, J. (1965). A City Is Not a Tree. Architectural Forum, 122, 58-62.

Cor Wagenaar, M. (2015). Town Planning in the Netherlands Since 1800 (pp. 212).

Ewart, G., \& Culpin, M. (1993). Garden City Movement Up-to-Date (pp. 8).

Graham Livesey, J. (2011). Assemblage Theory, Gardens and the Legacy of the Early Garden City Movement. arq: Architectural Research Quarterly, 7, 271-278. https://doi.org/10.1017/S1359135511000819

Gu, K. (2001). Urban Morphology: An Introduction and Evaluation of the Theories and the Methods. City Planning Review, 25.

Howard, E. (1985). Garden Cities of to-Morrow (New Illustrated Edition of 1902 Book). Eastbourne, UK: Attic Books.

Huang, Z. M. (2014). The Study of European Contemporary Urban Residential Form and Design Strategy (pp. 70). China Architecture Design and Research Group.

Jan Gehl, M. (2010). Cities for People (Ouyang, W., \& Xu, Z., Translated). Beijing: China Building Industry Press [Denmark].

Perry, C. A. (1929). The Neighbourhood Unit (Monograph I), Neighborhood and Community Planning, of the Regional Survey of New York and Its Environs. Vol.7. New York: In Committee on Regional Plan of New York and Its Environs.

Stephen, V., \& Ward, J. (1992). The Garden City-Past, Present and Future (p. 24).

Teng, S. H. (2007). New Urbanism and Suitable Residential Areas.

Zhao, S. G. (2007). The Development of Western Contemporary Urban Design Thoughts and the Development of Residential Community Design in China (p. 14). Tianjin: Tianjin University School of Architecture. 